\title{
CLINICAL USES OF 2,3-DIMERCAPTOPROPANOL (BAL). XI. THE TREATMENT OF ACUTE MERCURY POISONING BY BAL ${ }^{1}$
}

\author{
By WARFIELD T. LONGCOPE AND JOHN A. LUETSCHER, JR., with the ASSISTANCE \\ oF EVAN CALKINS, DAVID GROB, STEWART W. BUSH, \\ AND HARRY EISENBERG \\ (From the Medical Clinic of Johns Hopkins University and Hospital, Baltimore)
}

(Received for publication February 5, 1946)

The extensive investigations upon the mechanism by which arsenic poisons the protoplasm of cells $(1,2)$ and the discovery (1) that the di-thiol, 2,3-dimercaptopropanol or BAL (British AntiLewisite), possesses an avidity for Lewisite and trivalent arsenicals, thus sparing injury to the cells and their essential enzymes, led to the suggestion that the toxic action of other metals might be explained in a similar manner. Evidence is now at hand to show that the principles involved in the injurious effect produced by mercury and cadmium are analogous to those ascribed to arsenic (1 to 3 ).

It has, in addition, been amply demonstrated (4) that BAL is a highly effective antidote to acute mercury poisoning in rabbits and dogs. In order to obtain complete or even partial protection against the poisonous effect of mercury bichloride, BAL had to be administered shortly after the injection of mercury; but when the first intramuscular dose of $\mathrm{BAL}$ was given 5 minutes after the intravenous injection of an amount of mercury bichloride fatal to the control animals, all of the rabbits survived. If, on the other hand, an interval of 30 minutes had elapsed, only about $3 / 4$ of the animals could be saved. In dogs, however, this interval could be prolonged, and when the lethal dose of mercury bichloride was given by mouth, BAL proved to be an effective antidote after the lapse of several hours. In one series of experiments, 3 of 5 dogs survived a lethal oral dose of mercury bichloride when the first intramuscular injection of BAL was made 5 hours later, followed by subsequent injections at 2 and 4 hours.

From the information available it seemed desirable to test the efficacy of BAL in the treat-

1 This work was carried out under a contract, recommended by the Committee on Medical Research, between the Office of Scientific Research and Development and Johns Hopkins University. ment of acute mercury poisoning in man. This paper, therefore, presents the observations made on 23 patients who were admitted to The Johns Hopkins Hospital with a history of having swallowed from 0.5 gram to 20 grams of mercury bichloride, and who were treated with BAL. ${ }^{2}$

On admission to the accident ward of Johns Hopkins Hospital, the stomach was lavaged with 5 or 10 per cent sodium formaldehyde sulfoxylate, and $300 \mathrm{mgm}$. of a 10 per cent solution of BAL in benzyl benzoate and peanut oil was injected intramuscularly. One to 2 hours after this initial dose the patient was given $150 \mathrm{mgm}$. of BAL, which was usually followed in 4 to 6 hours by another dose of $150 \mathrm{mgm}$. In several patients still a third dose of $150 \mathrm{mgm}$. was injected before 12 hours had elapsed. In this manner, 3 patients received $450 \mathrm{mgm}$. of BAL in 12 hours; 12 patients received $600 \mathrm{mgm}$; one patient, $620 \mathrm{mgm}$.; and 5 patients, $750 \mathrm{mgm}$. During the second 12 hours the patients usually received 1 , or often 2 , injections of BAL. Thereafter, 2 doses of $150 \mathrm{mgm}$. a day were given, as a rule, for 1 to 2 days or more, depending somewhat upon the general condition of the patient. The total amounts of BAL given 18 patients ranged from $1200 \mathrm{mgm}$. to 2870 mgm, the majority (14) receiving between 1200 mgm. and $1950 \mathrm{mgm}$.

Since many of the patients were young women weighing between 45 and $65 \mathrm{kgm}$., the first dose of BAL was somewhat larger than is usually advised ( 5 to 7 ), for it has been stated that an injection of $5 \mathrm{mgm}$. per $\mathrm{kgm}$. gives rise to toxic

2 We are greatly indebted to the Baltimore City Hospital, the South Baltimore General Hospital, the West Baltimore General Hospital, the University Hospital, the Union Memorial Hospital, the Mercy Hospital, the Provident Hospital, and especially to the Police Department for the excellent co-operation which they gave in transferring patients to the Johns Hopkins Hospital for treatment. 
symptoms in about 50 per cent of normal men. In many of our patients the first injection of 300 $\mathrm{mgm}$. amounted to $5 \mathrm{mgm}$. per $\mathrm{kgm}$., and in a few, to $7 \mathrm{mgm}$. per $\mathrm{kgm}$., and a total of the doses administered in the first 12 hours would often have been unwarranted except for the extremely serious condition of the patients. These rather excessive amounts of BAL were given with considerable trepidation, but symptoms of intoxication proved uncommon. One patient developed tingling of the tongue following the last few doses of 150 mgm., and an occasional patient complained of abdominal pain within 20 minutes after the first injection. In many patients a rise in blood pressure was recorded during the first 24 or 48 hours, but in the absence of other symptoms it is dubious whether this change can be ascribed to the injections of BAL. ${ }^{3}$

Immediately after admission to the hospital a series of special examinations were instituted. The vomitus, stools and urine were collected during the first few days for qualative analysis of mercury by Mr. Harry Eisenberg. Repeated chemical analyses of the blood were made by Mrs. White and her asistants. Non-protein nitrogen, chlorides, $\mathrm{CO}_{2}$, calcium and phosphorus of the blood, and the total plasma proteins with their albumin and globulin fractions were determined repeatedly in most patients. Estimations of the phenolsulfonephthalein excretion and urea clearance were usually made on several occasions.

A summary of the essential data concerning the condition of the 23 patients is recorded in Table

\footnotetext{
${ }^{8}$ Since the completion of this paper, 3 patients have shown rather pronounced reactions after 1 or more doses of BAL. One woman weighing $58 \mathrm{kgm}$. who had swallowed 1.5 grams of bichloride of mercury, experienced flushing of the face, fullness in the head, dizziness, sweating, shooting pains in arms and legs, burning of mouth and throat, and pain in epigastrium after the first dose of $300 \mathrm{mgm}$. of BAL, which amounted to $5.1 \mathrm{mgm}$. per $\mathrm{kgm}$.; subsequent doses of $150 \mathrm{mgm}$., or $2.5 \mathrm{mgm}$. per $\mathrm{kgm}$., gave no untoward symptoms. A second woman weighing $44 \mathrm{kgm}$. who had swallowed $0.5 \mathrm{gram}$ of bichloride of mercury suffered from flushing of the face and $a b-$ dominal pain after the first dose of $300 \mathrm{mgm}$. of BAL, which represented $6.8 \mathrm{mgm}$. per $\mathrm{kgm}$. The second and third doses of $150 \mathrm{mgm}$. or $3.4 \mathrm{mgm}$. per $\mathrm{kgm}$., produced no symptoms. The fourth dose of $150 \mathrm{mgm}$. was followed by flushing and cardiac irregularity due to extra systoles. A third patient was observed to have extra systoles following a single dose of $150 \mathrm{mgm}$. of BAL given late in the course of treatment.
}

I, and the results of the determinations of the electrolytes of the blood, the urea clearance and the phenolsulfonephthalein excretion are listed in Table II.

In addition to the tabulated data it was noted that all of the patients had a slight elevation of temperature during the first 24 to 48 hours after admission. The urinary output was somewhat reduced in many cases during the first 12 hours or more after admission, but the moderate oliguria did not persist in any patient, except the one who died, for more than 24 hours. At least 4 patients, including the fatal case, were admitted in shock and required transfusions of blood in addition to the usual infusions of physiological salt solution and 5 per cent glucose. A moderate elevation of blood pressure during the first 24 or 48 hours was common.

The cases have been arranged in Table $I$ according to the amount of mercury bichloride which each patient swallowed, 8 having taken 0.5 gram or less, 6 having taken 1.0 gram, and 9 having swallowed from 1.5 grams to 20 grams. This dose was determined from information gained from several sources, but the circumstances under which some of these patients swallowed the tablets, or drank the fluid containing powder, often rendered it difficult to be certain of the exact amount swallowed.

A somewhat more detailed analysis of these groups shows, as might be expected, that the symptoms at onset, as well as the findings on admission and the clinical course during the first few days of observation, varied considerably from group to group.

The first group of 8 patients swallowed only 1 tablet, or 0.5 gram of mercury bichloride. This dose is said to be rarely, if ever, fatal. None of these patients appeared seriously sick. None showed blood in the stool and only 1 showed blood in the vomitus. Four of 5 cases in which the stools were examined gave positive tests for mercury, but mercury was not found in the vomitus of 3 , or in the urine of any of the 5. Small amounts of albumin were found in the urine of 6 ; none in the urine of 2 . None were in shock on admission, and hemoconcentration was not noticeable, although 1 patient (No. 6) had a hematocrit reading of 51 . Only 2 patients showed a leukocyte count of over 15,000 per $\mathrm{cu} . \mathrm{cm}$. The 


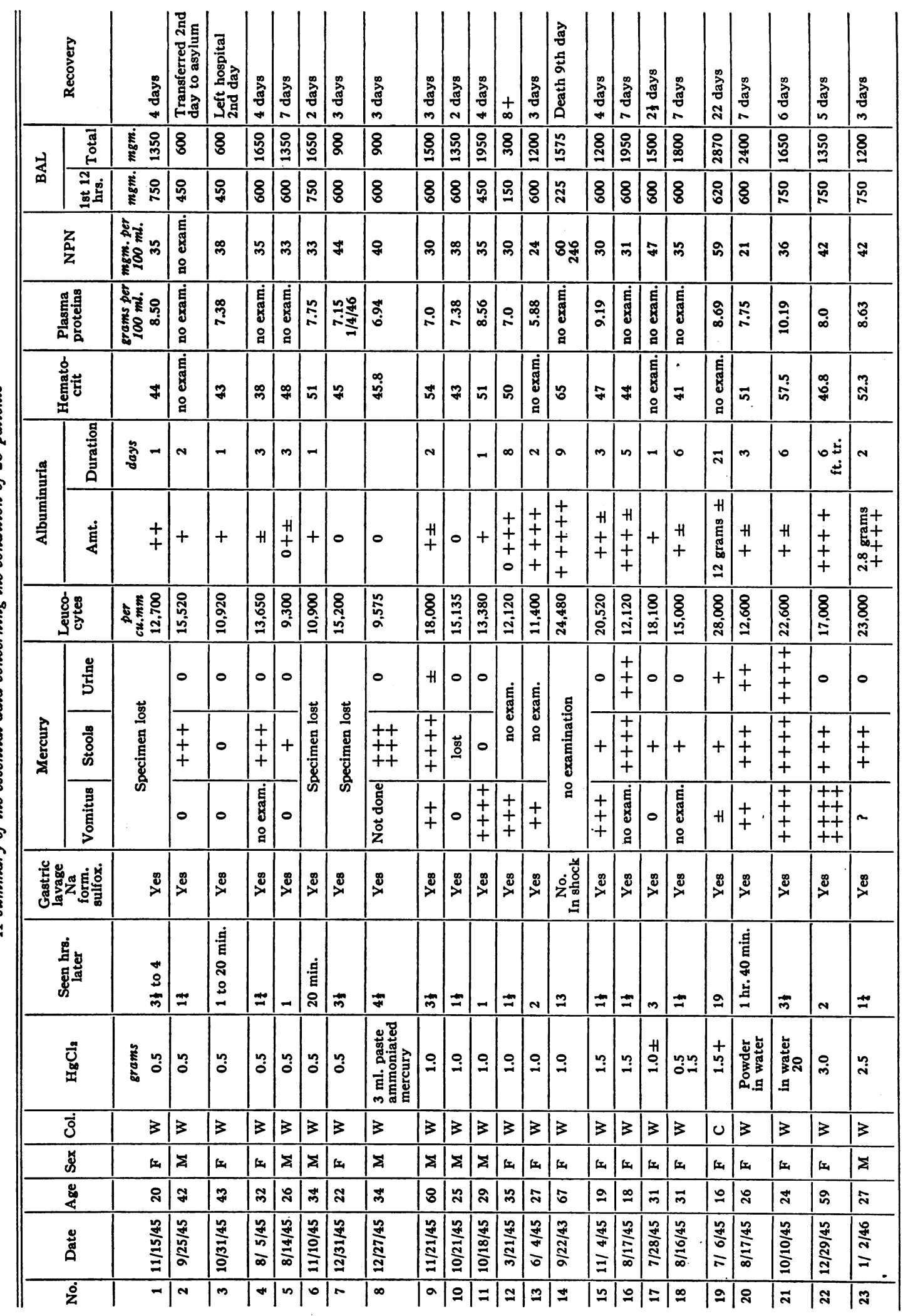


WARFIELD T. LONGCOPE AND JOHN A. LUETSCHER, JR.

TABLE II

The results of determinations made on 23 patients.

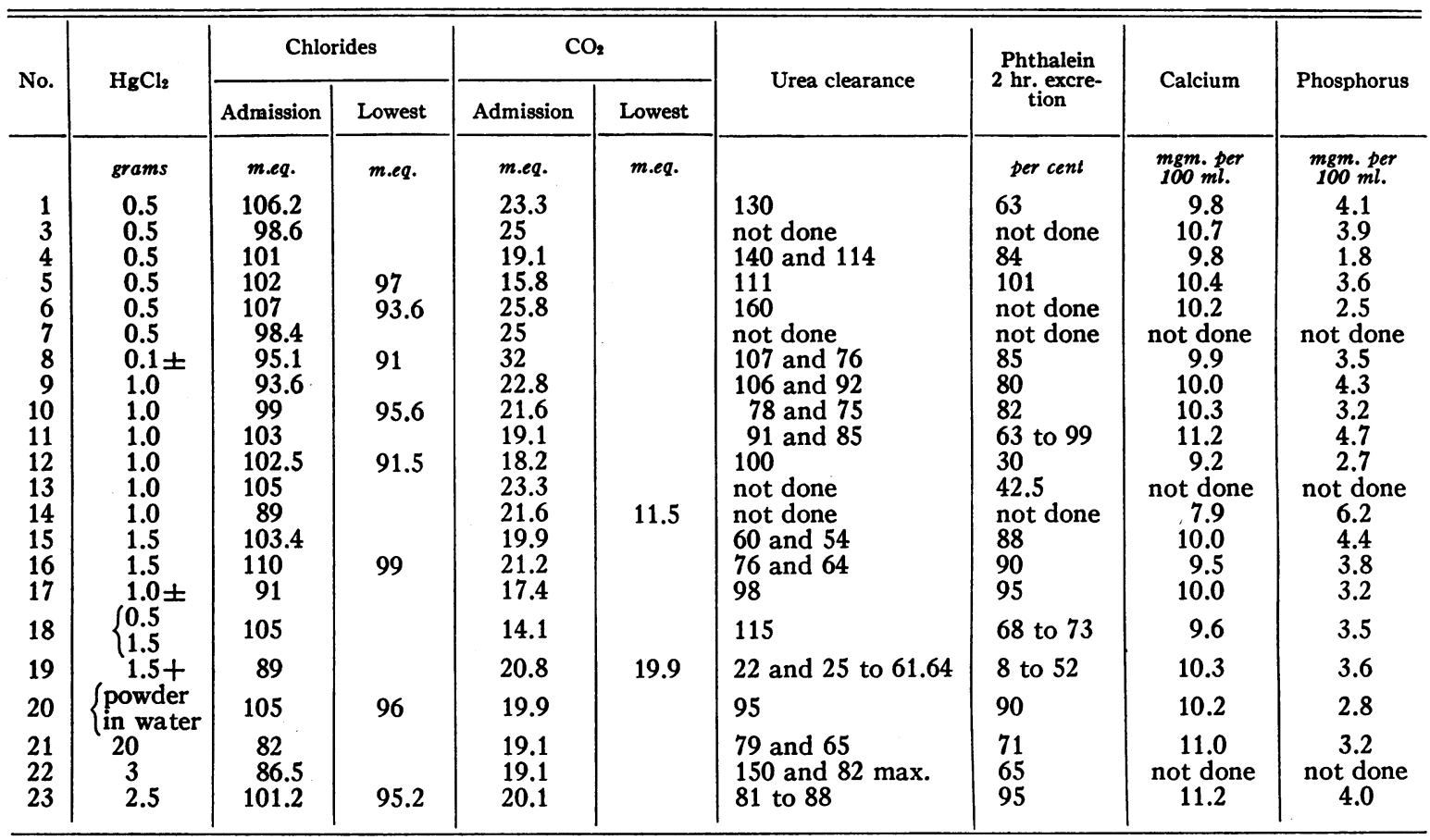

The number of cases correspond to those in Table I.

TABLE III

H.B. w.f. age 32 No. 359135 Adm. August 5, 1945, 11:45 p.m.

\begin{tabular}{|c|c|c|c|c|c|}
\hline *August & 5 & . & 7 & 8 & 9 \\
\hline $\begin{array}{l}\text { Blood pressure } \\
\text { Leukocytes cu. mm. } \\
\text { Hematocrit } \\
\text { Fluids, ml. } \\
\text { Urine, ml. } \\
\text { Albumin } \\
\text { Red blood cells } \\
\text { Casts } \\
\text { Mercury } \\
\text { Vomit \{ \{lood } \\
\text { mercury } \\
\text { Stools }\left\{\begin{array}{l}\text { No. } \\
\text { blood } \\
\text { mercury }\end{array}\right. \\
\text { Phthalein } 2 \text { hr. excretion } \\
\text { N.P.N., mgm. per } 100 \mathrm{ml} \text {. } \\
\text { CO. m.eq. } \\
\text { Chlorides m.eq. } \\
\text { Urea clearance } \\
\text { BAL mgm. } \\
\text { BAL total }\end{array}$ & $\begin{array}{c}8,000 \\
38 \\
1,500 \\
110 \\
\pm \\
0 \\
0 \\
2 \\
+ \\
1 \\
0 \\
\\
35 \\
19.1 \\
101.0 \\
450\end{array}$ & $\begin{array}{l}110 / 80 \\
130 / 90 \\
13,650 \\
36.6 \\
5,730 \\
4,950 \\
+ \pm \\
0 \\
\pm \pm \\
00 \\
0\end{array}$ & $\begin{array}{c}4,750 \\
3,750 \\
\pm 0 \\
0 \\
\pm \\
0 \\
\\
0 \\
\\
23 \\
25.8 \\
108.0 \\
300\end{array}$ & $\begin{array}{c}7,400 \\
38.4 \\
5,120 \\
5,590 \\
0 \\
0 \\
\pm \\
0 \\
0 \\
\\
0 \\
\\
\\
92 \text { per cent } \\
30 \\
26.6 \\
104.0 \\
160 \\
150\end{array}$ & $\begin{array}{r}1,120 \\
525 \\
0 \\
0 \\
0 \\
0 \\
\\
1 \\
0 \\
0\end{array}$ \\
\hline
\end{tabular}

Case 4, Table I. Wt. $59 \mathrm{kgm}$. One and three-quarter hours before admission to Johns Hopkins Hospital she had swallowed 1 tablet of bichloride of mercury $(0.5 \mathrm{gram})$. She vomited the tablet, swallowed it again and then drank a cup of coffee. There was severe epigastric burning. She was taken to Baltimore City Hospital a little later, where the stomach was lavaged with sodium formaldehyde sulfoxylate. She was then transferred to Johns Hopkins Hospital.

* All 24-hour determinations in these tables are calculated from midnight to midnight. 
non-protein nitrogen of the blood in one was 40 mgm. per cent; in another, $44 \mathrm{mgm}$. per cent. But in the other 5 patients in which this determination was made, the figures were within normal limits. Recovery was rapid. Table III shows the course of 1 of these patients.

The second, or intermediate group, comprises 6 patients who swallowed 2 tablets, or 1.0 gram of mercury bichloride. The symptoms on admission were much more serious than in the first group. Diarrhea and persistent vomiting were common. Blood was present in the vomitus of 2 and in the stools of 2 . In 1 of these the diarrhea was grossly bloody. Mercury was found in large quantities in the stools of 1 of 2 patients, and in the urine of 1 of 3 patients. One patient was admitted in collapse (No. 12), 1 in profound shock (No. 14) 13 hours after having taken 2 tablets of bichloride and having slashed her wrists. This patient, the first, treated with inadequate amounts of BAL, died 9 days later. There was evidence of hemoconcentration in 4 patients, the hematocrit being 50 or above in all of these. The leukocyte counts ranged from 15,000 to over 24,000 per cu. $\mathrm{cm}$. in 3 , and there was well marked albuminuria in all but 1. Except in the fatal case, recovery took place rapidly in all but No. 12, who was the second case treated, and who received inadequate doses of BAL, a total of only $300 \mathrm{mgm}$. Table IV records the detailed study of 1 patient in this group, and Figure 1 depicts the course of the fatal case.

The third group of 9 patients was admitted to the hospital in a condition that was considered to be serious, and in some, actually critical. Five had swallowed at least 3 tablets ( 1.5 grams) of bichloride; 1,5 tablets (2.5 grams), 1, 6 tablets (3.0 grams) ; 1, an unknown quantity of powder in water; and one, at least 20 grams in water. One patient was not admitted to the hospital until 19 hours after taking 3 tablets (1.5 grams) of bichloride. In the meantime she had only been treated with eggs and milk. The remaining 7 patients were admitted from $1 \frac{1}{4}$ to $31 / 2$ hours after

TABLE IV

J.C.McC. w.m. age 60 No. 269218 Adm. Nov. 21, 1945, 7:55 p.m.

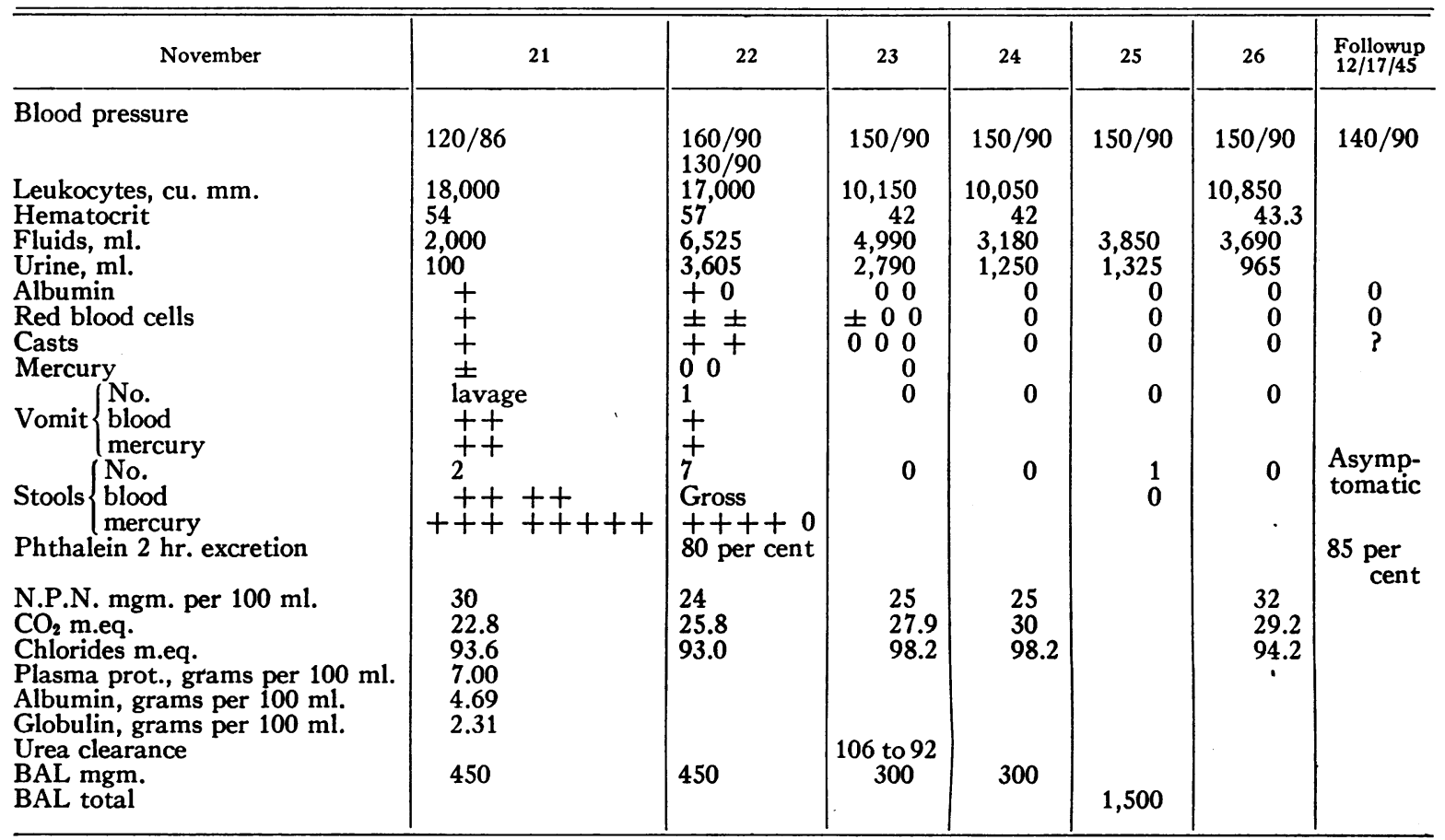

Case 9, Table I. Admitted to Johns Hopkins Hospital $3 \frac{1}{2}$ hours after swallowing 2 tablets of bichloride of mercury (1.0 grams). Twenty minutes after taking the tablets he vomited once. On admission the stomach was lavaged with $4000 \mathrm{ml}$. of 5 per cent sodium formaldehyde sulfoxylate. Within $\frac{1}{2}$ hour he had abdominal cramps and tenesmus with bloody, watery diarrhea. 


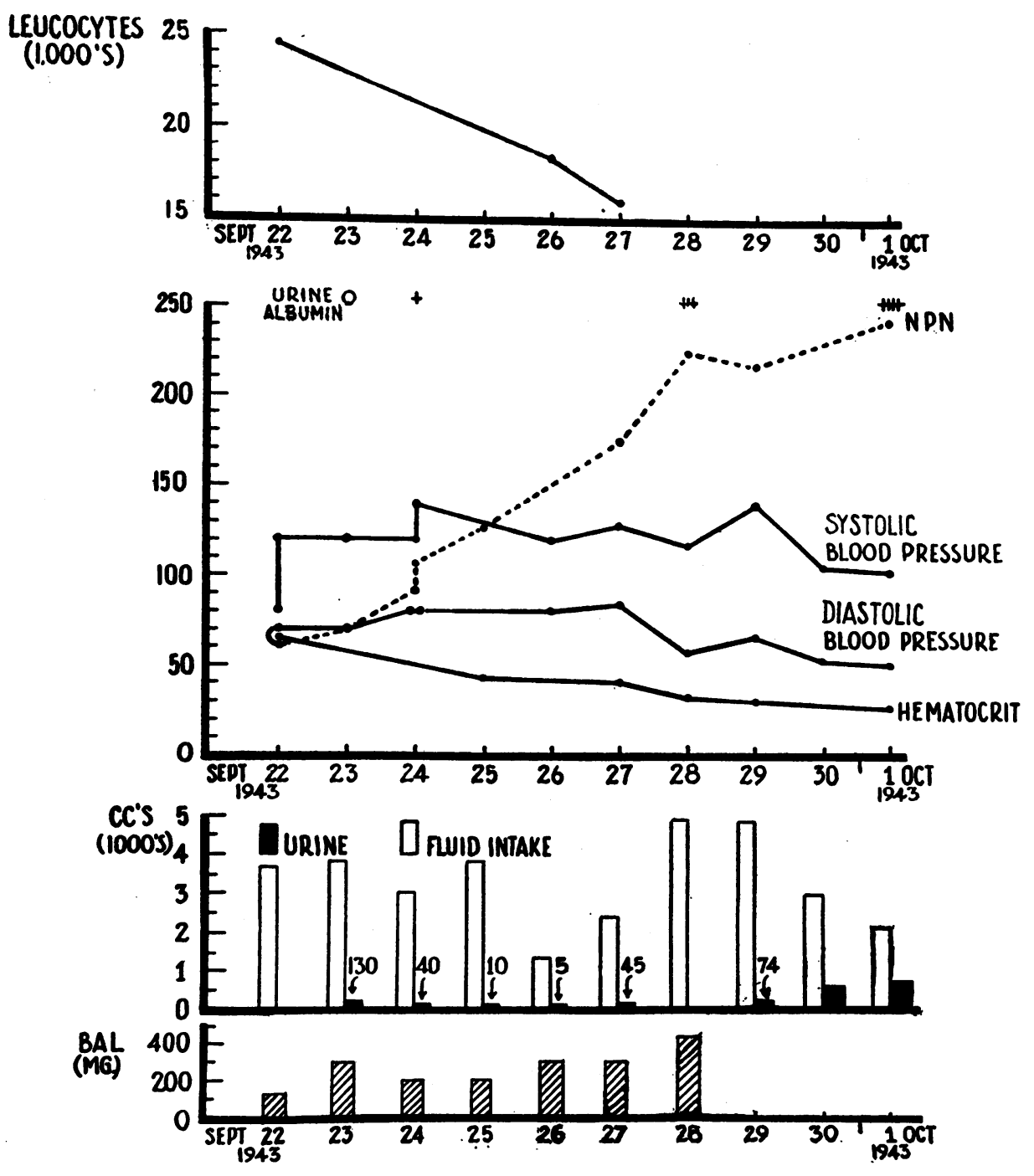

Fig. 1. CASE 14, TABLE I

Female, white, age 67, No. 224094, admitted to Johns Hopkins Hospital Sept. 22, 1943. Her right kidney had been removed in 1933 and she had had palpitation and shortness of breath for 1 year. Thirteen hours before admission at 7 a.m. she had taken 2 tablets $(1.0 \mathrm{gram})$ of bichloride of mercury and had slashed her wrists. The stomach was lavaged with sodium formaldehyde sulfoxylate 8 hours after taking bichloride. She had vomited small amounts of bloody material. She had voided only once. On admission she was unconscious and in shock, the pulse unobtainable, the blood pressure 80/60, respirations 36 and temperature $101.4^{\circ}$. Lavage of the stomach was again performed; she was given $1000 \mathrm{ml}$. of plasma intravenously, and digitalis. She was anuric. Within 48 hours the condition of the circulation had improved and the blood pressure had risen to $140 / 80$.

swallowing the bichloride, and had received lavage with 5 per cent sodium formaldehyde sulfoxylate either before admission or on admission to the hospital. Most of them showed hemoconcentration, the plasma proteins in 1 being 9.19 grams per $100 \mathrm{ml}$; and in another, 10.19 grams per 100 $\mathrm{ml}$. At least 3 were in shock and required transfusions of blood as well as intravenous infusions of saline and 5 per cent glucose. The vomitus was bloody in 6; the diarrheal stools, bloody in 5 . 
The leukocytes varied from 15,000 to 28,000 per cu. $\mathrm{cm}$. in 7 patients and were above 20,000 in 4 of these. All showed considerable amounts of albumin, casts and red blood cells in the urine on admission, and the non-protein nitrogen of the blood was somewhat elevated in 3 and increased to $59 \mathrm{mgm}$. per cent in 1 other. It was in this group also that the blood chlorides were most notice-

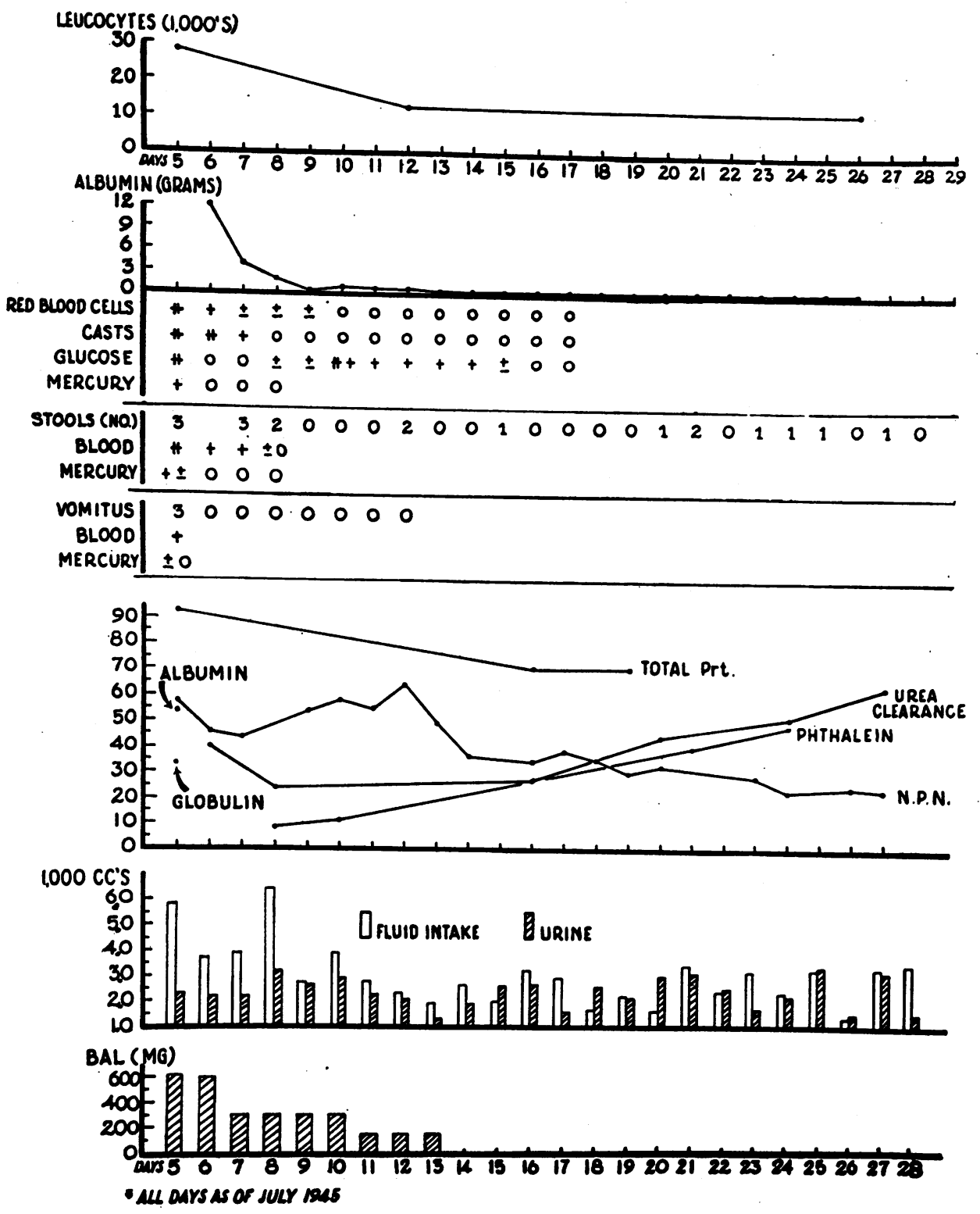

Fig. 2. Case 9, Table I

Female, colored, age 16, admitted to Johns Hopkins Hospital July 6, 1945, No. 356389, wt. 120 lbs. At 10 p.m. on July 4, 19 hours before admission, she had taken 3 tablets ( 1.5 grams) of bichloride of mercury in water. Fifteen minutes later she drank 3 quarts of milk and vomited. Milk and eggs were administered after 1 to 2 hours. Vomiting continued and was bloody by 4 a.m. July 5 . Abdominal pain continued and she became drowsy. On admission the stomach was lavaged with 5 per cent sodium formaldehyde sulfoxylate, and physiological salt solution and 5 per cent glucose administered intravenously. She passed 2 bloody stools. She was stuporous and showed pitting edema. 
ably reduced, the lowest figure being $82 \mathrm{~m}$. eq. This was also true of the blood bicarbonate, the lowest figure being $14.1 \mathrm{~m}$. eq.

The sudden and favorable change that took place in the condition of these patients in 48 hours was often unexpected. All of them except 1 (No. 19), were symptomatically well within 2 to 3 days, and 8 had recovered entirely with $2 \frac{1}{2}$ to 7 days. Complete restitution to normal did not occur in No. 19, who was admitted to the hospital 19 hours after taking 3 tablets of bichloride of mercury, until 22 days, though she was free of all symptoms at the end of 2 weeks.

Figure 2 presents in detail the course of the illness in this patient; and Table V, the course in 1 other patient in this group.

The evidence that we have been able to collect through the study of these 23 patients supports the contention that BAL is capable of neutralizing the toxic action of unusually large doses of mercury bichloride. The effects are most striking when BAL is administered intramuscularly in comparatively large amounts within $3 \frac{1}{2}$ hours after the ingestion of mercury bichloride. Under these circumstances the kidney appears to be spared serious or lasting injury, even when mercury can be detected in the urine for many hours after the ingestion of the mercury bichloride. Our observations in man, therefore, are in accord with the experimental results reported by Gilman and coworkers (4).

The outcome in any case of poisoning by bichloride of mercury is conditioned by many factors, some of which are quite beyond control; and it is therefore very difficult to estimate the value of one form of treatment, or a combination of methods, in a series of cases as small as this. The recognition (8) of the loss of electrolytes and the dan-

TABLE V

M.F. w.f. age 24 No. 256736. Adm. Oct. 10, 1945, 10:40 p.m.

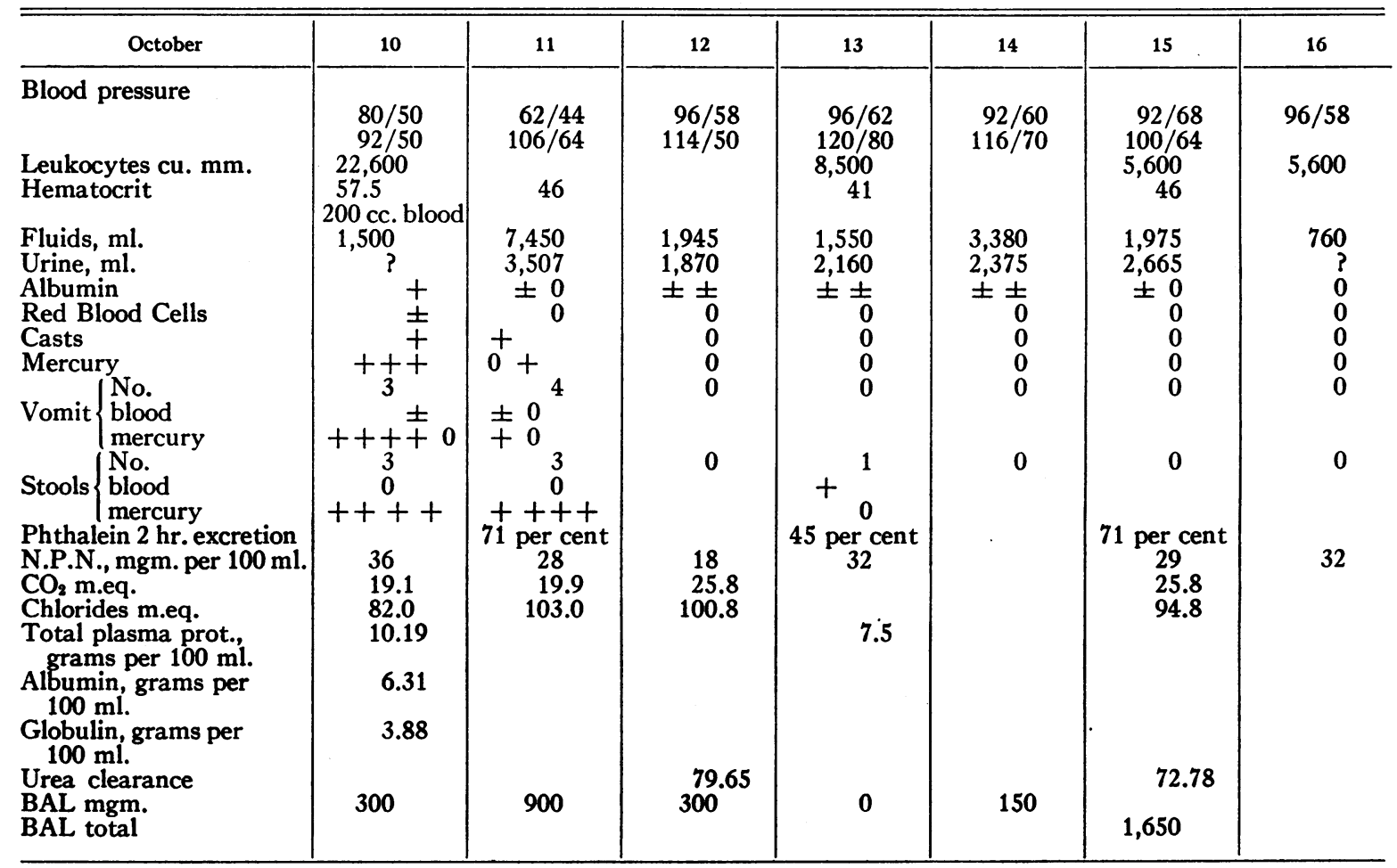

Case 21, Table I. Wt. $94 \frac{3}{4}$ lbs. Admitted to Johns Hopkins Hospital $3 \frac{1}{3}$ hours after drinking warm water containing about 20 grams of bichloride of mercury. She had emptied a box containing 30 grams of bichloride of mercury into a glass of water, stirred and drank all but the dregs. She then had abdominal cramps and nausea. Later she drank milk and eggs and started vomiting about $\mathbf{4 0}$ minutes after drinking bichloride of mercury. On admission to the hospital the stomach was lavaged with $4000 \mathrm{ml}$. of 5 per cent sodium formaldehyde sulfoxylate. She was in shock and required 2 transfusions of blood. 
ger of shock in the early stages, together with the introduction of the use of intravenous infusions of physiological salt solution and glucose, reinforced by transfusions, when necessary, marked a distinct advance in therapy which has been employed in our patients. The introduction (9) of gastric lavage with solutions of sodium formaldehyde sulfoxylate marked a still further step in advance, and though the value of this antidote has been questioned, we have availed ourselves also of its aid.

It is, however, very difficult to determine from the published data that any of these methods have, in the hands of many observers, resulted in a significant reduction in mortality when amounts of mercury bichloride greater than 1.5 grams were swallowed ( $9 \mathrm{~b}$ to 11$)$.

It has been generally stated (12) that a dose of 0.5 gram of mercury bichloride by mouth is rarely, if ever fatal; that when 1.0 gram is swallowed and vomiting does not occur within 10 minutes, the prognosis is poor (13), and that 1.5 grams often results in death.

In 263 cases of bichloride of mercury poisoning admitted to Johns Hopkins Hospital from 1925 to $1945,{ }^{4}$ there have been 34 deaths (12.9 per cent). One fatality ( 4.4 per cent) occurred in the 23 cases treated with BAL and described in this report. While this manuscript was being prepared, 2 additional patients were treated with BAL and made a rapid recovery. Including these cases, there has been 1 fatality in 25 cases ( 4.0 per cent). Because the severity of poisoning influences the fatality rate so greatly, we have divided the patients into groups according to dosage of poison, proteinuria, and leukocytosis on the day of admission. These features were chosen because they could be quickly determined, and appeared to have

4 Treatment has been modified during this period by more effective fluid replacement, and by the use of sodium formaldehyde sulfoxylate intravenously and by gastric and colonic lavage. Although the fatality rate in the recent cases is less than half that observed previously, there is still doubt concerning the effect of these treatments, because the dosage of poison has been generally smaller in the more vigorously treated patients. The division of cases according to dosage leads to rather small groups, in which a statistical analysis by Miss Sarah F. Lawler showed no significant effect of treatment. We have therefore considered all cases of bichloride poisoning prior to the use of BAL as a single group. some prognostic value $(11,14$ to 17$)$. In the control series, increasing dose, leukocytosis, and proteinuria are associated with increasing fatality rates. The severity of poisoning in the group receiving BAL, as indicated by the distribution of cases in Figure 3, appears somewhat greater than in the control series. The number of cases is too small for satisfactory statistical treatment, and only a preliminary impression of the value of BAL can be given.

It can be said, however, that the 23 cases presented in this study include patients representing many different examples of poisoning by mercury bichloride, ranging from the mildest types to those which appeared to be extremely serious, both on account of the amount of bichloride of mercury swallowed and the intensity of symptoms on admission. Perhaps the most significant effect of the treatment was the prompt relief of even the most alarming symptoms when BAL in sufficient doses was administered within 3 to 4 hours after mercury bichloride had been swallowed, and the rapidity with which the patients made a complete recovery. ${ }^{5}$

\footnotetext{
5 Since the completion of this paper 19 additional patients suffering from acute mercury poisoning have been treated with BAL. Six of the patients had swallowed 0.5 grams of mercury bichloride, eight 1.0 gram and five from 1.5 to 3 grams. The intensity of the acute symptoms, the height of the leukocyte count and the degree of albuminuria and demonstrable damage varied considerably, but were most pronounced in those patients who had swallowed 1.5 grams of mercury bichloride or more. All but one of these 19 patients recovered. The fatality occurred in a woman of 55 who had taken 2.0 grams of mercury bichloride five to six hours before admission to the hospital.

A review of the entire series of 42 patients treated with BAL, emphasizes the great importance of instituting this form of therapy within the first few hours after the patient has swallowed mercury bichloride. Two of five patients in which the injections of BAL could not be started until 6 to 42 hours had elapsed died. All 37 patients, irrespective of the size of the dose and intensity of symptoms, treated within 4 hours after they had swallowed mercury bichloride recovered. This point is well brought out in a comparison of the series of patients treated by BAL with an analogous control group admitted to the Johns Hopkins Hospital before the use of BAL. Since all the patients in both groups who had swallowed only 0.5 grams of mercury bichloride or less recovered, these have been excluded. There were 86 patients in the control group who were admitted within 4 hours after swallowing 1.0 gram or more of mercury bichloride. Of
} 


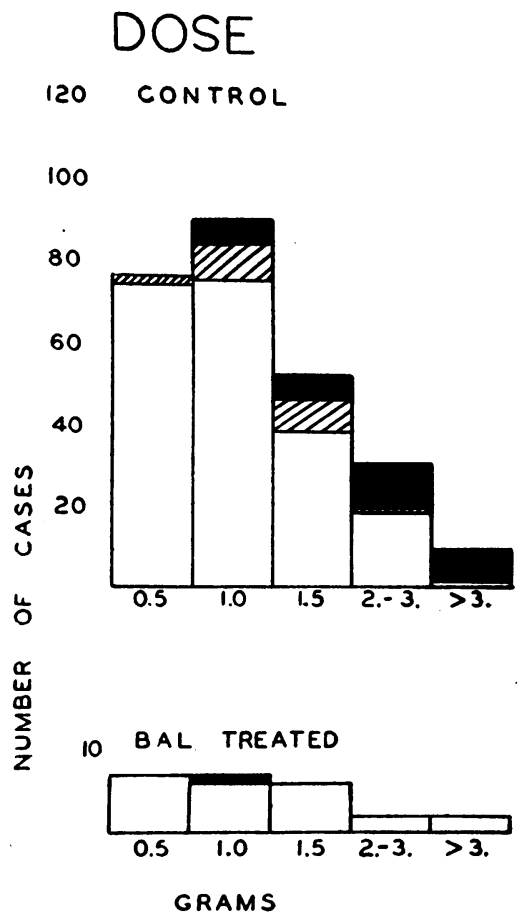

\section{W.B.C.}
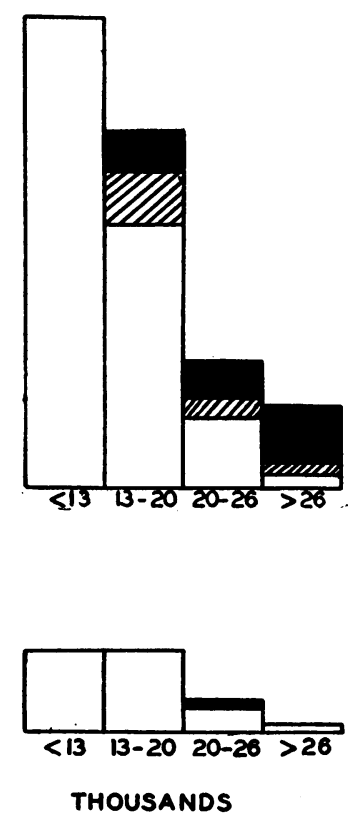
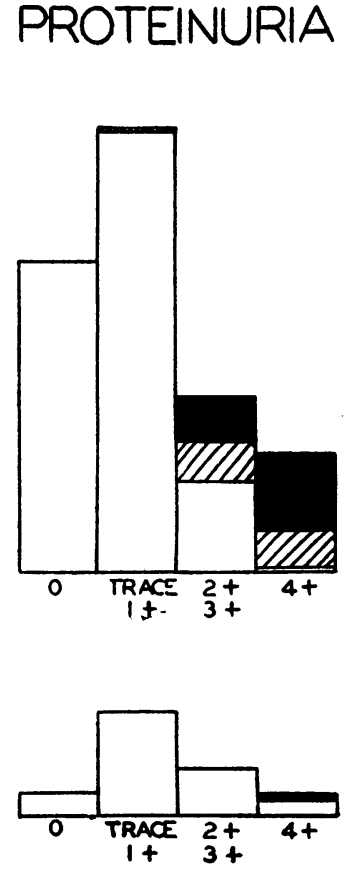

Fig. 3. Distribution of Cases of Poisoning by Bichloride of Mercury According to Dosage, Leukocytosis, and Proteinuria

The height of each column represents the number of cases with the particular dose, white blood count, or urinary protein noted below. Fatal cases are indicated in black, persistent renal damage (proteinuria or reduced renal function on subsequent examinations) in shaded areas, and recovery in white. The upper chart represents 263 cases not treated with BAL. The lower chart represents 25 cases treated with BAL. In the control series, the increasing fatality rates with increasing dose, leukocytosis, and proteinuria, are evident. The BAL series shows evidence of a probably greater severity of poisoning, as judged by these prognostic signs.

\section{SUMMARY}

Twenty-three cases of acute poisoning by mercury bichloride have been treated with intramuscular injections of BAL. Eight of these patients swallowed not more than 0.5 gram of mercury bichloride, and treatment with BAL was started from 20 minutes to $3 \frac{1}{2}$ hours later. All made a prompt recovery.

Six patients swallowed 1.0 gram. Five were

these 27 died. There were 25 patients in an analogous group treated by BAL with no deaths.

Comparison of fatalities in a control group of patients who swallowed 1.0 gram or more of mercury bichloride and were admitted to the Johns Hopkins Hospital within 4 hours and an analogous group treated with BAL:

Control Cases

No.

86

24

Deaths treated within 1 to $3 \frac{1}{2}$ hours, all recovered within 2 to 8 days. One patient who was treated initially with small amounts of BAL 13 hours after taking 1.0 gram of mercury bichloride died on the ninth hospital day.

Nine patients took from 1.5 to 20 grams of mercury bichloride, 5 of the 9 having swallowed more than 1.5 grams. Eight patients were treated with BAL from $1 \frac{1}{4}$ to $3 \frac{1}{2}$ hours after taking the mercury, 1 patient was first treated 19 hours after having swallowed at least 1.5 grams. This patient was entirely well in 3 weeks, and the other 8 patients recovered completely in $2 \frac{1}{2}$ to 7 days.

The initial amount of BAL used for the first intramuscular injection in 21 patients was 300 mgm. ( 3 ml. of a 10 per cent solution). Two patients, including the 1 who died, received an initial dose of only $150 \mathrm{mgm}$. Twenty-one patients received from 450 to $750 \mathrm{mgm}$. in the first 12 hours, 
and a total of $900 \mathrm{mgm}$. to $2870 \mathrm{mgm}$. in a period of 3 to 4 days.

Toxic reactions attributable to $\mathrm{BAL}$ were observed in a few patients after the intramuscular injections of $300 \mathrm{mgm}$., or in some instances, 150 mgm., of BAL.

Considerable importance is attached to the prompt treatment by BAL in an initial intramuscular injection of $300 \mathrm{mgm}$., followed within the first 12 hours by 2 or even 3 further injections of 150 mgm. each.

\section{BIBLIOGRAPHY}

1. Peters, R. A., Stocken, L. A., and Thompson, R. H. S., British Anti-Lewisite (BAL). Nature, 1945, 156, 616.

2. Waters, L. L., and Stock, C. C., BAL (British AntiLewisite). Science, 1945, 102, 601.

3. Barron, E. S. G., and Kalnitsky, G., Inhibition of succinoxidase by heavy metals. Reactivation with dithiols. To be published.

4. Gilman, A., Allen, R. P., Philips, F. S., and St. John, E., The treatment of acute systemic mercury poisoning in experimental animals with BAL, thiosorbitol and BAL glucoside. J. Clin. Invest., 1946, 25, 549.

5. Sulzberger, M. B., Baer, R. L., and Kanof, A., Studies on the toxicity of BAL on percutaneous and parenteral administration. J. Clin. Invest., 1946, 25, 474.

6. Eagle, H., and Magnuson, H. J., The systemic treatment of 227 cases of arsenic poisoning (encephalitis, dermatitis, blood dyscrasias, jaundice, fever) with 2,3-dimercaptopropanol. Ann. of Syph., Gonor. \& Ven. Dis. (in press).

7. Modell, W., Gold, H., and Cattell, M., Pharmacologic observations on BAL by intramuscular injection in man. J. Clin. Invest., 1946, 25, 480.
8. Peters, J. P., Eiseman, A. J., and Kydd, D. M., Mercury poisoning. Am. J. M. Sc., 1933, 185, 149.

9a. Rosenthal, S. M., Experimental studies on acute mercurial poisoning. Pub. Health Rep., 1933, 48, 1543.

b. Ibid., An antidote for acute mercury poisoning. J.A. M. A., 1934, 102, 1273.

c. Ibid., The use of sodium formaldehyde sulfoxylate in acute mercury poisoning. J. Pharmacol. and Exper. Therap., 1935, 54, 34.

10a. Hull, E., and Monte, L. A., Bichloride of mercury poisoning; a statistical study of 302 cases. South. M. J., 1934, 27, 918.

b. Hull, E., and Monte, L. A., The treatment of acute mercuric chloride poisoning. Ann. Int. Med., 1935, 9, 54.

c. Monte, L. A., and Hull, E., Mercury bichloride poisoning treated with sodium formaldehydre sulfoxylate: results in 40 cases. J. A. M. A., 1940, 114, 1433.

11. Wolpaw, R., and Alpers, N., The treatment of acute mercury poisoning with sodium formaldehyde sulfoxylate with review of 20 cases. J. Lab. and Clin. Med., 1942, 27, 1387.

12. Sollman, T., Manual of Pharmacology. W. B. Saunders, Philadelphia, 1942.

13. Goodman, L., and Gilman, A., The Pharmacological Basis of Therapeutics. Macmillan \& Co., New York, 1941.

14. Porter, W. B., and Simons, C. E., The treatment of bichloride of mercury poisoning: a study of 46 cases. Am. J. M. Sc., 1934, 188, 375.

15. Goldblatt, S., Acute mercurial intoxication. Report of 38 cases. Am. J. M. Sc., 1928, 176, 645.

16. Mintz, E. R., Some remarks on the treatment of bichloride poisoning with a presentation of 21 cases. New England J. Med., 1933, 208, 1189.

17. Peters, $H$. R., Suicide from the ingestion of mercury. M. Clin. North America, 1941, 25, 403. 